\title{
DE LA ESCLAVITUD A LA LIBERTAD: LAS VOCES DE MORISCAS Y MORISCOS EN LA GRANADA DEL SIGLO XVI
}

\author{
Aurelia Martín Casares
}

El interés por la esclavitud en la España Moderna empezó a cobrar auge en los años 50 con el trabajo pionero de Antonio Domínguez Ortiz ${ }^{1}$ que versaba sobre la esclavitud en Castilla. Éste primer germen encontró su eco a través de los trabajos de V. Cortés Alonso ${ }^{2}$ sobre Valencia, y a partir de entonces empezaron a surgir diversos estudios locales, siendo las zonas más estudiadas Murcia, Valladolid, Córdoba, Málaga, Sevilla, Almería y Canarias ${ }^{3}$. La ubicación geográfica de estos trabajos no es fortuita sino que está

1. Domínguez Ortiz, A., «La esclavitud en Castilla durante la Época Moderna», Estudios de Historia Social en España, Tomo II, pp. 367-428, 1952. A este trabajo pionero se unen otros estudios parciales del fenómeno publicados también en los años 50, ver: GUAL CAMARENA, M. «Un seguro contra crímenes de esclavos», Anuario de Historia del Derecho Español, pp. 457458, 1952. Larrea Palacín, A., «Los negros de la provincia de Huelva», Archivo del Instituto de Estudios Africanos, ${ }^{\circ}$ 20, 1952. LOPEZ EstraDA, F., «Bautismo de esclavos en Antequera 1614-1624», Anales de la Universidad Hispalense. XI, pp. 39, 41. 1950. MARRERO RODRÍGUEZ, M., «De la esclavitud en Tenerife», Revista de Historia, $\mathrm{n}^{\circ}$ 100, pp. 428-441, 1952. MATA CARRIAZO, J., "Negros, esclavos y extranjeros en el barrio sevillano de San Bernardo", Archivo Hispalense, $\mathrm{n}^{\circ} \mathrm{XX}$, pp. 64-65, 1954.

2. CORTÉs Alonso, V., «La esclavitud en Valencia durante el reinado de los Reyes Católicos 1479-1516», 1964; id., "La liberación del esclavo», Anuario de Estudios Americanos, $\mathrm{n}^{\circ}$ XII, pp. 533-568; id., «La población negra de Palos de la Frontera (1568-1579)», Actas y Memorias del XXXVI Congreso Internacional de Americanistas 1966. Para esta misma década podemos ver: LADERO QUESADA, M.A., "La esclavitud por guerra a fines del siglo XV: el caso de Málaga», Hispania, $\mathrm{n}^{\circ} 77$, pp. 63-88, 1967 y PIKE, R., "Sevillian society in the sixteenth century: slaves and freedmen», Hispanic American Historical Review, n 47 , pp. 344-359, 1567.

3. Cabrillana CIÉZAR, N., «Esclavos moriscos en la Almería del siglo XVI», Al Andalus, $\mathrm{n}^{\circ} \mathrm{XI}$ pp. 53-128, 1975; id., "La esclavitud en Almería según los protocolos notariales (15111550)", Actas del congreso de Metodología en las Ciencias Históricas, vol. V, 1975; para Málaga, véase: BENITEZ SÁNCHEZ-BLANCO, R., "Guerra y sociedad: Málaga y los niños moriscos cautivos", Estudis, vol. III, 1974; para Valencia: GRAULLERA SANZ, V., La esclavitud en Valencia en los siglos XVI y XVII, Diputación Provincial de Valencia, 1976 y KAMEN, H., «Mediterranean slavery in its last phase: the case of Valence 1660-1700», Anuario de Historia Económica $y$ Social, pp. 211-234, 1970; para Córdoba NDAMBA KABONGO, A., Les esclaves à Cordue au debut du XIléme siècle (1600-1621), Tesis de doctorado, Universidad de Toulouse-Le-Mirail, 1975; 
directamente relacionada con una mayor concentración de personas esclavizadas en esas regiones de la península ibérica, especialmente en Andalucía. Sin embargo, no existe aún ningún estudio sobre la realidad de la esclavitud en Granada ${ }^{4}$, área especialmente privilegiada en cuanto a la presencia de moriscos esclavizados se refiere. Por otro lado, si la voz de los esclavos granadinos se ha dejado sentir en muy pocas ocasiones, aún menos frecuente es encontrar la de libertos y libertas.

En estas páginas, me limitaré a analizar las fuentes para el estudio de las moriscas y moriscos libertos en la Granada del XVI y puntualizaré ciertos aspectos significativos del proceso emancipatorio sin entrar en valores globales.

Como sabemos, a partir de 1568 y debido a la rebelión de las Alpujarras, la mayoría de las personas esclavizadas en la Granada Moderna son moriscos y moriscas rebelados, originarios del propio Reino de Granada. Es decir, personas que en el mismo espacio geográfico habían sido libres unos meses antes, y que se han convertido en esclavas. Esta guerra modifica en cierto modo el patrón de esclavitud existente en la península dando lugar a numerosos abusos, sobre todo por parte de la gente de guerra (soldados, capitanes, etc.) que ven en la esclavitud una manera de hacer fortuna.

Por otro lado, el uso del masculino genérico ("moriscos, esclavos") en la gran mayoría de los trabajos de investigación realizados hasta hoy, enmascara un hecho que se hace patente para cualquier estudioso/a que se acerque a los Archivos: la gran mayoría de las personas esclavizadas en la guerra de las Alpujarras fueron mujeres. Pero este fenómeno no es particular a la Granada Moderna, sino que se repite en numerosos contextos ${ }^{5}$. Por ello, es imprescindible tener en cuenta los últimos avances metodológicos y conceptuales que se están llevando a cabo desde perspectivas feministas englobadas institucionalmente en los Estudios de la Mujer. Si bien es cierto que los datos que ofrezco se refieren mayoritariamente a testimonios femeninos como prueba de la abundancia de mujeres (esclavas, libertas e incluso propietarias), también debemos tener en cuenta que los propios documentos del siglo XVI no se olvidan de ellas y a menudo hablan de "esclavos y esclavas" 6 .

para Canarias: LOBO CABRERA, M., «La esclavitud en las Canarias orientales en el s. XVI», Santa Cruz de Tenerife, 1982; para Sevilla: Franco Silva, A., Esclavitud en Andalucía 15401550, Granada, 1992 y para Salamanca: LOPEZ BENITO, C. J., «La sociedad salmantina en los inicios del siglo XVI. Los esclavos», Actas del II Congreso de Historia de Salamanca, Tomo II,1992.

4. Espero que mi tesis: La esclavitud en la Granada del siglo XVI, dirigida por Bernard Vincent (E. H. E.S. S) y Cándida Martínez (Universidad de Granada), venga a cubrir esta laguna en breve.

5. En palabras de F. Andujar: "Pero en propiedad, desde el punto de vista cuantitativo, más que hablar de esclavos moriscos hemos de referirnos a las esclavas". ANDÚJAR CASTILLO, F., «Del esclavo morisco al berberisco. Sobre la esclavitud en la Almería del siglo XVII», Boletín del Instituto de Estudios Almerienses, (1992-93), p. 84.

6. Existen numerosos casos, citemos por ejemplo el siguiente texto: "la mayor parte de la gente iba con intención de robar e mercadear. . y otros muchos llevaron muchos dineros y 
La primera cuestión a tratar para adentrarnos en el proceso emancipatorio de la Granada Moderna sería: ¿qué son los libertos/as? Pues bien, las libertas y libertos que nos ocupan son personas que previamente han estado sujetas a cautiverio y servidumbre, y que, por diversas razones, como veremos más adelante, son manumitidas por sus dueños y dueñas. Seguirles la pista es enormemente difícil, ya que su condición de liberto/a no siempre viene expresada en los documentos. Además las razones de su liberación son muy diversas y la heterogeneidad entre el grupo de personas liberadas es amplia.

Comenzaré por analizar el impacto de la rebelión de 1568 en la realidad de la esclavitud granadina para continuar con algunas precisiones sobre el estatus de liberto/a. Más adelante comentaré las fuentes indirectas, en las que encontramos noticias sobre libertos y libertas expresadas sobre todo a través de sus propietarios y terminaré describiendo algunas fuentes directas en las que descubrimos a estas personas liberadas actuando por sí mismas.

\section{REBELIÓN Y LIBERACIÓN}

Empezaremos por analizar cómo modifica la rebelión de las Alpujarras (1568-71) el patrón de la esclavitud y las liberaciones de moriscos y moriscas, teniendo en cuenta que la guerra ofrece un maravilloso botín humano a los soldados y capitanes cristianos que participan en ella y sin olvidar que los intereses de estas "gentes de guerra" eran sobre todo económicos por lo que no dudan en hacer dinero con la mercancía humana.

Los abusos producidos en la guerra se hacen patentes a través de una Pragmática Real de 1572, que refiriéndose a los moriscos "tomados en lugares de paz o hurtados", versa así: "Y mandamos que los que con malicia, sabiendo y auiendo venido a su noticia que no se podian vender, los herraron, vendieron y dispusieron dellos como si fuesen esclavos, sean pugnidos y castigados, segun la calidad de su culpa"7.

Existe incluso cierta confusión legal sobre quiénes podían ser o no esclavizados en época de la rebelión, hasta el punto que ciertos compradores se muestran cautos a la hora de hacer sus transacciones. Tal es el caso del propietario del pequeño Juan, morisco, que un soldado de la guerra vendió a un mercader granadino y éste a su vez lo vendió en Toledo a un dorador en 1569. El nuevo dueño ha oído del bando de su majestad que prohíbe la escla-

encomiendas de sus amigos para comprar de las cabalgaduras que habian de hacer, esclavos y esclavas y ropas de seda" de la Crónica de Andrés Bernáldez, Historia de los Reyes Católicos don Fernando y Doña Isabel; citado por GARCíA PASTOR, V., «La esclavitud en Castilla durante el reinado de los reyes católicos», Conflictos sociales y evolución económica en la Edad Moderna, Toledo, 1988, p. 9.

7. La expulsión de los Moriscos del Reino de Granada. Pragmáticas, provisiones y ordenes reales. 1572 . 
vitud infantil y quiere demandar al vendedor, pero por quitarse de pleitos llegan a un acuerdo ${ }^{8}$.

Efectivamente la Pragmática existe y dice así: "y otrosi que en quanto a los dichos moriscos menores de la dicha edad de diez años y medio los varones, y de nueve y medio las mugeres. Declaramos que aquellos conforme a lo por nos ordenado no fueron esclavos de los que los tomaron, ni de aquellos a cuyo poder ha venido y que las ventas y otros qualquier contratos y disposiciones que dellos se ouieren hecho han sido y fueron ningunas" ${ }^{\prime \prime}$.

Por lo tanto, queda clara la ilegalidad en que se incurría al cautivar niños y niñas moriscos, y más aún al cobrar dinero por su rescate. Otra cuestión importante, que no voy a analizar en estas páginas, consiste en analizar las causas que llevan a los legisladores a imponer el estado de esclavitud un año antes para las niñas.

En cualquier caso, este desconocimiento de las leyes, lleva a los moriscos a pagar altas sumas por liberar a menores. Lope el Manco y Lope Xarril, labradores de Biznar, pagan nada menos que 81 ducados por liberar a la pequeña Isabel de 7 años ${ }^{10}$ que ni siquiera debía haber sido esclavizada.

Otro aspecto importante ligado a la época de la rebelión y años posteriores, era la solidaridad entre los moriscos que se hace patente en los documentos principalmente a través del pago del rescate por parte de otros moriscos: miembros de la familia o amigos. Quizá, esto tenga que ver con el concepto de assabiya o solidaridad entre los miembros de una misma tribu extendida a los miembros de un colectivo musulmán.

Efectivamente, en la Granada del XVI, encontramos numerosos rescates pagados por familiares de las personas esclavizadas o por otros moriscos solidarios. El dueño de Ysabel de Cozbijar, morisca de 50 años, aclara que "a tratado con beatriz rrodriguez su hija del rescate de la dicha su madre" en 45 ducados $^{11}$; y en 1573, Francisco Pérez Alazar se ve obligado a pagar 100 duca-

8. Archivo de Protocolos de Granada (en adelante APG) fol. 224v, 1569: "Pero Lopez dorador vezino de toledo estante en granada digo que Fco de Nabarrete mercader vezino de granada estando en Toledo me vendio un esclabo Juan de ocho o nuebe años poco mas o menos de los moriscos deste rreyno de granada que ubo e compro de Mesa soldado vezino de Ecija por 374 rreales que por el pague en Toledo el nuebe de mayo de 1569 y por la dicha escritura el dicho Fco de Navarrete esta obligado a quel dicho Juan sera esclavo y me servira como tal esclavo y a causa que como es notorio sea echado bando en esta çibdad por mandato del exmo sr don Juan de Austria que siendo los esclabos que se han tomado deste rreyno de hedad de 20 años queden libres por cuya causa queria poner demanda al dicho Fco de Nabarrete los dichos 364 rreales que yo le queria volver su esclabo y por quitarnos de pleitos e deferençias somos convenidos y concertados en que por razon de pretension que tengo contra el dicho Fco de Nabarrete por razon del dicho bando me de e pague 10 ducados y que con ello yo quede por contento".

9. AMG, Pragmática y declaración sobre los moriscos menores del reyno de Granada. En Madrid En casa de Alonso Gómez Impresor de su Magestad, 1572.

10. $\mathrm{APG}, \mathrm{n}^{\circ} 169$, fol. $464 \mathrm{v}, 1569$.

11. APG, $n^{\circ} 197$, fol. 640,1574 . 
dos para liberar a su hija Ysabel y a sus dos nietas, Luysa y Maria, las tres esclávas moriscas en poder de Gaspar de Mercado, capellán y vecino de la colación de la Iglesia Mayor, que fueron compradas a comienzos de la guerra.

A veces encontramos un morisco que rescata a un niño porque "lo quiere criar y alimentar" 12 sin que se especifique ninguna relación de parentesco.

Estas personas solidarias o familiares de las esclavas y esclavos moriscos estarían dispuestas a pagar un precio mayor del que adquirirían en el mercado, constituyendo de esta manera otra fuente de ingresos sustanciosa para los propietarios. Tomemos por ejemplo el caso de una anciana de 60 años llamada María, "de los moriscos rebelados de Durcal", por la que Sebastian Velasco Eldali que vive en Granada paga 43 ducados $^{13}$.

En contraposición con esa imagen de solidaridad entre los moriscos, y para ilustrar la complejidad de las relaciones de dominación, encontramos propietarios y propietarias de esclavos/as que son cristianos nuebos como es el caso de Leonor Aboambra viuda de Francisco el Fayar que vive en la colación de San Juan de los Reyes y decide liberar en su testamento a Gaspar Díaz, esclavo nacido en Granada de color membrillo cocho, "porque su marido se lo dijo e aconsejo muchas vezes"14. Interesante también es el caso de Isabel Dubayaxa que no sabe castellano y libera a su esclava María de 8 años aunque antes deberá servir 10 años y aclara "por el buen serviçio que me a fecho". Además libera a Juan de 15 años boçal que deberá servir 3 años ${ }^{15}$. Si bien es cierto que la tendencia más común entre los moriscos es tener esclavos negro-africanos (bozales).

Según los ejemplos expuestos queda clara la importancia de la guerra en cuanto al impacto que produce en el patrón de la esclavitud existente anteriormente y su devenir histórico.

\section{EL ESTATUS DE LIBERTO/A}

En segundo lugar, analizaremos el estatus de "liberto/a". Para comprender la situación de las personas liberadas, lo primero que debemos tener en cuenta es que la transmisora del estatus de esclavo/a o libre es la mujermadre. El padre en la mayoría de los casos es desconocido y aún siendo libre, no transmite su estatus a los hijos. Por ejemplo, cuando en 1569, Pedro de Avila, tundidor y vecino de Granada, redacta ante el escribano la carta de

12. APG, fol. $314,1569$.

13. APG, $\mathrm{n}^{\circ} 171$, fol. $395 \mathrm{v}, 1569$.

14. $\mathrm{APG}, \mathrm{n}^{\circ} 119$, fol. $248 \mathrm{v}, 1561$.

15. $\mathrm{APG}, 1542$, fol. 958 , testamento. 
horro de su esclava morisca Ana, de 35 años, quiere que ésta le pague 110 ducados por su rescate. Como Ana no dispone de tanto dinero ya que se trata de una suma muy importante en la época, su dueño le permite que "el rescate se lo vaya pagando poco a poco aunque sea en reales" y hasta que no termine de pagar el último ducado "no sea libre ni horra sino cautiba y sujeta a servidumbre". Pero, además se incluye otra condición en el contrato: "que si la dicha Ana al presente esta preñada o se preñase que aquello que pariere no abiendo pagado todo el rescate a de ser y es cautibo y para el dicho Pedro de Abila"16. Por lo tanto, queda claro que el estatus del recién nacido depende directamente del de su madre.

Otro punto a tener en cuenta sería que el estatus de liberta/o no debe asimilarse simétricamente al de persona libre ya que las personas manumitidas se encuentran estigmatizadas por su pasado esclavo y no podían librarse tan fácilmente del mismo. De hecho su calidad de ex-esclavo/a está claramente presente en su vida y se expresa en los documentos a través de fórmulas como: "esclavo que fue de...", "que de poco aca es horra...", "que es horro y fue esclavo...", etc. De esta manera, a través de ciertas frases, se consigue marcar y distinguir a los libertos/as de las personas que han nacido libres. Así, cuando Diego el Dubily "de color moreno", labrador, compra un pedazo de viña de secano de 2 marjales a otro labrador de Albolote, en la escritura de compraventa se aclara "esclavo que solía ser de Luys eldubili"17. Por lo tanto, aunque Diego esté actuando por sí mismo y como persona libre, su antiguo estatus de esclavo sigue estando presente.

Además, por muy libre que fuese uno, el tono oscuro de la piel llevaba a confusiones. Una cristiana, granadina y viuda, que hace testamento a finales del siglo XVI nombra como herederos a dos hermanos (hombre y mujer) y aclara que "tienen en su color de rostro alguna sospecha para entender que sean cautivos digo y declaro que no lo an sido ni son sino personas libres". Con esto quiero ilustrar que a pesar de que la sociedad granadina del XVI estuviese más o menos acostumbrada a la diversidad de tonos de piel, sí que se hacían asociaciones entre oscuridad de piel y esclavitud ${ }^{18}$.

Es frecuente encontrar autores que dividen a las personas esclavizadas en negros y blancos, asimilando los moriscos exclusivamente a los blancos. Si bien es cierto que la mayoría de los moriscos y las moriscas son blancos, la realidad es que hay numerosos negros; como Ysabel "negra natural de las Alpujarras" liberada por Sebastián el Muli, un carpintero granadino en 1569, cuando ella contaba con 50 años" 19 y mulatos, como Inés "mulata de las albu-

16. $\mathrm{APG}, \mathrm{n}^{\circ} 171$, fol. $394,1569$.

17. $\mathrm{APG}, \mathrm{n}^{\circ} 150$, fol. 68,1566 .

18. Es interesante el análisis que hace del racismo y el Islam Bernard LEwis en Race et couleur au pays d'Islam, Ed. Payot, París, 1982.

19. APG, no 171, fol. 112, 1569. 
ñuelas" liberada por un mercader granadino junto con su hija Leonor "mujer de Mateo Vilchez el Natax" que estaba preñada y su nieto Miguel "hijo de Felipa Auli"20.

No sólo no se debe asimilar siempre el término morisco a blanco, sino que a menudo resulta difícil constatar con seguridad la procedencia morisca de algunas personas libertas. En numerosas ocasiones, se olvida el hecho de que las personas esclavizadas llevan el apellido de sus dueños, lo cual implica que si el dueño es morisco, la esclava llevará también un apellido morisco aunque ella misma no sea de origen morisco. Por lo tanto, queda claro que al llevar el apellido del dueño no siempre sabemos si los libertos/as son realmente moriscos o han sido esclavos de moriscos. Es el caso de "Gostança Firyha", negra liberta, que fue esclava de Fdo el Fery, y es muger de "Gonzalo Hadid", moreno que fue esclavo de Francisco el Hadid, y que aparece en un documento notarial comprando un pedazo de viña de "hasta un marjal con sus olibos" 21 .

En cuanto al futuro de las personas liberadas, las diferencias por razones de género son evidentes, y aunque no pretendo llevar a cabo en estas páginas un análisis profundo de esta realidad, esbozaré algunas de estas diferencias. Por ejemplo, el empeño en casar a las mujeres libertas es común y muy poco frecuente en el caso de los varones. En numerosos documentos se hace patente la preocupación por legar cierto dinero o bienes para ayuda a la dote de la esclava y en otros, no menos numerosos, se encarga a algún familiar que les busque esposo. Habría que analizar este empeño en casar a las libertas.

Por otro lado, es mucho más frecuente encontrar varones que han aprendido un oficio con el que ganarse la vida que mujeres, lo cual no quiere decir que la productividad femenina sea menor, sino que está infravalorizada y no reconocida socialmente. Cuando Diego de Moya, alpargatero, libera a un morisco esclavo señala que ha aprendido el oficio de cordonero ${ }^{22}$.

Quizá, esas condiciones adversas de vida llevasen a algunas libertas a la prostitución, ya que es relativamente frecuente el miedo a "que se pierdan" referido a las mujeres en los testamentos. Pongamos por ejemplo el caso de una cristiana soltera que al testar quiere que su "morisca", Luisa, sea libre tras servir 6 años a su sobrina; además le da ropa de casa y pide que la casen "por que sea buena muger y sirva a dios" 23 .

20. APG, $n^{\text {"1 }} 169$, s. f. 1569 .

21. APG, $\mathrm{n}^{\circ} 150$, fol. $142 \mathrm{r}, 1566$.

22. APG, 1580: "yten declaro que yo e tenido e tengo en mi poder a Luys que es morisco y me a servido mucho tiempo en mi casa e le he mostrado mi ofiçio de cordonero mando que el susodicho se quede en poder de Catalina Alonso mi muger y cuando haya seuido dos años despues de mi fallçimiento se le de su libertad".

23. Testamento de Francisca de Tuesta. APG, s.f., 1580. 
Así, la viuda Clara de Pareja expone en su testamento el deseo de que su esclavo Luis de Medrano, nacido en su casa, sea libre y se convierta en clérigo, para lo que deja 12.000 maravedises de censo que deben ser administrados por un beneficiado; a María, esclava y hermana del anterior le deja sólo 2.000 maravedises para su casamiento, pero mientras tanto quiere que sirva en casa de una señora "que la adoctrine y castigue" y si "se ausentare" o porque "tenga sospecha de que no sirbe a dios" que "mys albaçeas y patron la puedan compeler como esclaba y metella en el monasterio del señor santiago de las monjas". La testadora sabe quién es el padre de los esclavos, pero no cita su nombre, sólo aclara que es cristiano viejo. Deja muy claro que no quiere que María salga con su padre y pretende que el hermano vele para que "no se pierda". En el caso de que María muera, los 2.000 maravedises serían para su hermano ${ }^{24}$. La diferenciación de género que hace la propietaria es patente: a) dándole una profesión al varón-esclavo y haciendo dependiente de un marido a la mujer-esclava, b) liberando a Luys de por vida y dejando abierta la posibilidad de que María vuelva a cautiverio y c) dándole 12.000 maravedises de censo a él y solamente 2.000 maravedises de dote a ella.

Otro factor importante sería que al liberar a una esclava-madre junto con su hijo o hija, ésta se ve obligada (al menos socialmente) a ocuparse no sólo de mantenerse a sí misma sino de criar a su prole. Para ilustrar que el coste de la crianza de los niños y niñas era elevado vemos cómo el propietario de un niño de 3 años llamado Alonso, hijo de su esclava, pide 40 ducados "para ayuda que con el e fecho en criallo"25. El número de madres liberadas con sus hijos e hijas, incluso recién nacidos, es bastante alto.

En caso de que los hijos/as sigan siendo esclavos/as, son las madres-libertas las que intentan en la mayoría de los casos rescatarlos. Empresa nada fácil y para la que tendrán que conseguir dinero. Una liberta llamada Isabel y probablemente enferma, que se casó siendo esclava y más tarde fue libera-

24. $\mathrm{APG}, \mathrm{n}^{\circ} 32,1532$, s. f: "yten digo y declaro que por quanto en mi casa naçio y yo he criado a luis sea libre de cautiverio e que nadie le pueda demandar agora ny en ningun tiempo y es mi voluntad que porque es hijo de un ombre de bien xptiano viejo que sea clerigo el dicho Luys de Medrano...". "yten mando que María my esclaba hija de María my esclaba quede libre e horra de todo cautiverio por amor de dios y porque dios perdone my anyma y por los buenos serviçios que de su madre rreçebi y que sy su hermano Luys de Medrano la quysiere para hazer por ella se la den libre para que la case y sy el dicho no la rresçibiere sirba a la señora Ginebra de Pareja por su soldada hasta en tanto que su hermano la demande o sea de hedad de casar y sy la dicha no la rresçibiere el patron y albaçeas la den a una persona a quyen sirba y que la doctrine y castigue... y que sy or causa se ausentare o por otra alguna que se tenga sospecha que no sirbe a dios que mys albaçeas y patron la puedan compeler como esclaba y metella en el monasterio del señor santiago de las monjas desta çibdad de granada para que las syrba como esclaba hasta en tanto que su hermano la quyera sacar y sy el dicho su hermano no hiziere por ella quede alli para syempre porque no se pyerda".

25. APG, $n^{\circ} 171$, fol. $696,1569$. 
da, explica que tuvo dos hijos que siguen en poder de su amo "por ser esclava cuando los tuvo" y deja a su marido encargado de que los rescate ${ }^{26}$.

No he encontrado ningún documento en que se libere un niño o una niña junto con el padre, que por otro lado, suele ser "desconocido" en los documentos. En las actas de bautismo podemos apreciar la ausencia de los padres ya que casi todos los niños y niñas esclavos bautizados son hijos de una "esclava y de la tierra" o "de (fulana) esclava y de la Santa Madre Yglesia", en rarísimos casos aparece el nombre del padre. Muchos de estos niños y niñas son probablemente fruto de la explotación sexual y las vejaciones de que eran objeto las esclavas.

En resumen podriamos decir que el estatus de las personas liberadas depende y varía según diversas circunstancias (socio-económicas, de género, etc.) y no existe homogeneidad en cuanto a su condición aunque sí tienen puntos en común. De lo anteriormente expuesto cabe destacar la existencia de notables diferencias entre el estatus de liberto/a y el de persona libre, y por tanto, la no-asimilación de ambos estados.

\section{FUENTES INDIRECTAS SOBRE LIBERTOS Y LIBERTAS}

Los documentos más importantes para el análisis de la presencia de libertas y libertos en la Granada del siglo XVI son las cartas de horro y los testamentos, los cuales se encuentran en los protocolos notariales.

Como veremos más adelante, la libertad conseguida podía ser total, condicionada por ciertas cláusulas del testamento, o parcial si los dueños o dueñas son varios. Empezaremos por presentar los citados documentos:

1) La "carta de horro" 27 : consiste en la concesión de la libertad a un esclavo o a una esclava por parte del dueño/a. La libertad normalmente se concede a cambio del pago de un rescate; en muy pocas ocasiones se libera gratuitamente. Normalmente, se especifica cómo llegó el esclavo a manos del propietario, luego se alegan las razones por las que se quiere liberar a esta persona, y se renuncia al derecho de servidumbre. Más adelante, se da poder

26. APG, fol. 561r, 1570-71: "yten digo y declaro que el dicho Juan Lopez mi marido antes que fuesemos casados tuvo mi amistad e conversacion e despues nos casamos antes que yo tuviese libertad e despues estando casados pago por mi rescate a Alonso de Carmona mi amo 90 ducados los pago el dicho Juan Lopez mi marido de su trabajo" "yten digo e declaro que antes que yo e el dicho mi marido no casasemos obimos por nuestros hijos a Juan e a Diego los quales estan en poder del dicho Alonso porque yo no habia conseguido libertad e por no ser abidos despues de casados sino antes lo declaro".

27. De la raíz árabe "harra"= emanciparse, ahorrarse (el siervo), ser libre; "hurr" = libre; "harrar" $^{\prime}=$ liberar, emancipar, manumitir, ahorrar. CORRIENTE, F., Diccionario árabe-español, Madrid, 1977, p. 150. 
a la persona liberada para que disponga de su voluntad y pueda hacer testamento. Y por último, el dueño/a se obliga a no revocar nunca la escritura.

Ejemplo de una carta de ahorría puede ser la que escritura el dueño de un morisco de 4 años, que "dize ser hijo de Diego Elzeyr y que es de los rebelados", en la que explica que lo compró de un soldado de la compañía del capitán Narváez "y de otros sus compañeros que me bendieron con una esclaba muger" y decide liberarlo por 30 ducados que paga Miguel Hernández Aximiez, otro morisco afincado en Granada ${ }^{28}$.

Efectivamente, el rescate podía ser pagado por otro morisco/a o por la propia persona sometida a cautiverio, que en algunos casos llegaba a reunir el dinero necesario por medio de algún trabajo, a través de las limosnas recibidas (una vez obtenida la licencia de su propietario para trabajar o mendigar), o sencillamente robando. En ciertas ocasiones, algunas personas muestran su agradecimiento por los servicios prestados regalando algún dinero a las esclavas para que puedan ir reuniendo los ducados necesarios y así poder comprar algun día su libertad. Un ejemplo de lo expuesto nos lo ofrece una doncella granadina que manda a Isabel, esclava de Alonso de Carmona seis ducados "para ayuda a su rescate", por que "ruegue a Dios por mi ánima y por los trabajos y serviçios que ha echo en mi enfermedad" $^{\prime 29}$.

Las fórmulas que se utilizan en el momento de la liberación: "por el amor que le tengo, por lo bien que me ha servido; por descargo de mi conciencia; por le fazer buena obra y en limosna", se repiten con monotonía. ¿Se trata realmente de móviles piadosos o de frases ya tipificadas? ¿Tienen los dueños/as conciencia de hacer un acto bueno liberando a las personas esclavizadas? En la mayoría de los casos, y a pesar de estos formulismos, no se libera gratuitamente, sino a través del pago de un jugoso rescate. Tomemos como ejemplo la manumisión de Ysabel Hatara, de 40 años y natural de las Albuñuelas, cuyo propietario, un calcetero granadino, la libera "porque tiene entendido que es buena cristiana", pero cobra 34 ducados por su rescate ${ }^{30}$.

Los manuscritos justifican que en el caso de las liberaciones infantiles, el motivo suele ser "que a naçido en my casa e porque lo e criado". A mi parecer, la razón de estas liberaciones podría estar relacionada con el hecho de que estos pequeños fuesen fruto de la explotación sexual de las esclavas por parte de sus dueños. Tomemos por ejemplo la liberación de un esclavillo por que "naçio en mi casa e lo he criado desde niño e le tengo mucho amor e porque lo pario una esclava mia"31.

\footnotetext{
28. $\mathrm{APG}, \mathrm{n}^{\circ} 171$, fol. $327,1569$.

29. $\mathrm{APG}, \mathrm{n}^{\circ} 129,1563$.

30. AGP, no 171, fol. 281v, 1569.

31. APG, fol. $733 \mathrm{v}, 1535$.
} 
Lo más común es que se libere gratuitamente a niñas y niños nacidos en casa de los amos. Otras veces, los ahorramientos gratuitos son reveladores de las intenciones por parte de los dueños de liberarse de una carga. Tal es el caso de Hernán Ximénez, mercader y cerero, que libera gratis a su esclava Ynes, nacida en Capileira, porque tiene 70 años y podemos presumir que ya no es productiva ${ }^{32}$. Aún más evidente es el caso de Simón, esclavo liberado "porque de presente el dicho Simon está tuerto de un ojo y esta quebrado en trabajando en el lagar del dicho don Juan Cigler Despinoza y así mismo es enfermo del pecho que echa sangre por la boca del trabajo que a tenido y no es de probecho ninguno"33.

El propio Cervantes critica severamente a los dueños que "ahorran y dan libertad a sus negros cuando ya son viejos y no pueden servir, y echándoles de casa con título de libres, los hacen esclavos del hambre, de quien no piensan ahorrarse si no es con la muerte" 34 .

Las cartas de ahorría eran utilizadas por los libertos y libertas como salvoconducto ante las autoridades, ésta es la razón por la que a veces se pide una copia. Este es el caso de Elvira ${ }^{35}$, una morisca de las Albuñuelas, que pide se le otorgue copia de su carta de horro varios meses después de ser liberada.

Otra manera de emancipar a las personas esclavizadas consistía en incluir cláusulas de libertad en los testamentos de los propietarios/as.

2) Los testamentos. En el caso de los testamentos, la liberación sólo era efectiva a partir de la muerte del testador como se expresa a través de la fórmula "desde el fin de mis dias".

La libertad concedida en los testamentos no siempre es total, sino que puede estar condicionada por ciertas cláusulas. La condición más común suele ser la de servir durante algún tiempo en casa de un familiar del testador/a. Tomemos por ejemplo el caso de Mayor Ximénez, cristiana y viuda de un cuchillero, que deja a su esclava morisca en poder de su hija hasta que muera y quiere que luego sea libre ${ }^{36}$. La "esclava que va a ser liberta" se convierte en una figura ambigua con un estatus transitorio muy interesante de analizar.

32. AGP, n 182 , s. f. 1571.

33. Documento citado por NDABA KABONGO, A., Les esclaves à Cordue au debut du XVIIe siècle (1600-1621), Tesis de doctorado en Historia, Universidad de Toulouse-Le-Mirail, p. 267.

34. Citado por: TARDIEU, Guy Jean-Pierre, Le noir dans la littérature espagnole aux XVIe et XVIle siècles, Tesis de doctorado, Bordeaux, 1977, p. 41.

35. APG, $\mathrm{n}^{\circ} 152$, s. f., 1569.

36. APG. fol. 485r, 1580. Testamento de Pedro de Córdoba: "yten mando que Bernardina mi esclaba morisca sirba a mi hija María de Almaçar mientras bibiere la dicha my hija y en fin de los dias de la vida de la dicha mi hija la dicha Bernardina quede libre e horra e quita de todo cativerio y serbidumbre". 
Tomemos el ejemplo de un abogado que tiene 3 esclavas (María, Ana y Catalina), hermanas e hijas de otra esclava suya, manda que sirvan a su mujer "todos los dias quella bibiera" y que luego sean libres "de la mitad que yo dellas tengo", sin embargo incluye una condición: "con cargo que no se case (su mujer) y si se casare que las dichas 3 esclabas sean libres y horras de la dicha mitad"37. De esta manera condicionaba el marido a su viuda a mantener su estado de viudedad.

Por consiguiente, numerosas veces la libertad conseguida es únicamente parcial. Este sería el caso de personas que pertenecen a varios propietarios/as y no todos/as deciden liberarlas. De hecho, una esclava se entiende como un bien ganancial del matrimonio, y al morir uno de los cónyuges puede liberar solamente la parte que le corresponde. Tal es el caso de la esclava Luysa, cuyo dueño la heredó de sus padres y decide darle la libertad, y dice: "que mi madre ya le abia dado aunque no my padre"38.

En cualquier caso las cláusulas referentes a personas esclavizadas que se pueden añadir al testamento, son de lo más variopintas. Tomemos por ejemplo el caso de Ysabel "muchacha de las moriscas rrebeladas deste reyno" que está obligada a ir a la sepultura de su ex-propietaria "todos los domyngos y fiestas de guardar a poner y quitar la çera"39 una vez liberada.

Pero no siempre los amos imponen condiciones a la hora de liberar a sus esclavas/os, hay quienes no sólo les dan libertad total sino que les dejan algún bien que generalmente es de poca cuantía. Un vecino de Restabal, le deja a su esclava morisca, Ysabel de Mendoça, "una colcha colorada e una caldera mediana e un colchon lleno de lana e un faldellin colorado que ella tiene y la cama en que ella duerme" ${ }^{\prime 4}$. En 1589, un boticario libera totalmente a su esclava Beatriz morisca que tiene 30 años "la qual a mas de 20 años que le sirve y le a servido muy bien y fecho muchos y muy buenos serviçios criandole sus hijos con mucho amor" ${ }^{\prime \prime 1}$. Beatriz fue otra víctima de la rebelión ya que entró a servir en 1568, cuando contaba con 10 años.

Por último, a las moriscas y moriscos esclavizados, siempre les queda como último recurso, la fuga, aunque no es demasiado frecuente y suele terminar en intento frustrado. Una de las esclavas fugitivas en época de la rebelión fue María "natural deste rreyno" de 24 años. Pero no llegó muy lejos porque los vecinos del pueblo donde María nació la reconocieron y la cautivaron de nuevo para traerla a vender a Granada ${ }^{42}$.

37. $\mathrm{APG}, \mathrm{n}^{\circ} 154$, fol. $130,1567$.

38. APG, $\mathrm{n}^{\circ} 178,1570-71$, fol. 284.

39. $\mathrm{APG}, \mathrm{n}^{\circ} 204$, s. f., 1576 .

40. $A P G, n^{\circ} 179$, s. f., 1576 .

41. $\mathrm{APG}, \mathrm{n}^{\circ} 281$, fol. $154 \mathrm{v}, 1589$.

42. APG, Legajo 181, 1571. s. f.: "y teniendo y poseyendo la dicha esclaba la susodicha en la dicha çibdad de ubeda se me fue e ausento y paresçe que se fue a la tierra del dicho lugar 
Hemos visto cómo a través de los documentos notariales, principalmente las cartas de horro y los testamentos de los propietarios/as podemos obtener una copiosa información sobre la realidad social de los moriscos y moriscas liberados.

\section{FUENTES DIRECTAS PARA EL ESTUDIO DE MORISCOS Y MORISCAS LIBERADOS}

Si ya es díficil encontrar documentos en que los moriscos hablen por sí mismos, aún resulta más complejo encontrar escrituras en las que podamos oír la voz de personas que han estado sometidas a esclavitud. No obstante, las líneas siguientes demostrarán que a pesar de todo existen algunos documentos en que libertos y libertas hablan por sí mismos.

En primer lugar, citaré las fuentes municipales, en las que en algunas ocasiones, aunque muy reducida, encontramos moriscos que ponen pleitos por su libertad. Las fórmulas suele ser más o menos del tipo: "se a tratado pleito de ysabel morisca de las rebeladas deste reyno de granada sobre razon que la susodica pide su libertad". En este caso es la propia Isabel la que pide se revise legalmente su situación de persona horra.

En segundo lugar, y a pesar de que numerosos historiadores consideran que las fuentes inquisitoriales representan un fondo viciado, citaré las fuentes del santo oficio. Estas fuentes son tan válidas como las demás, siempre que seamos conscientes de su contexto concreto, que no tendamos a generalizar a partir de las mismas y sobre todo, que no intentemos explicar un fenómeno exclusivamente a través de los fondos inquisitoriales, sino utilizando a la vez otras fuentes menos sesgadas.

De hecho aparecen libertas en los procesos de la Inquisición expresándose en primera persona, como es el caso de María Mexía ${ }^{43}$ "que de poco aca es horra y casada con Juan Alferez que es horro y fue esclabo". María es natural de Túnez y es sentenciada por pertenecer a "la secta de Mahoma". Parece ser que dijo "pues yo no creo en Dios mas valiera estar mora". Entre los testigos hay una esclava que nos presta su voz al declarar que María comulgaba sin confesar, que tenía un hombre por amigo y que los cristianos eran necios que les sabía la hostia a pan.

Otro ejemplo sería el de un liberto mulato, llamado Juan de Baeza que también fue procesado en 1570 porque "juraba por el miembro de dios y

de syerro a donde çiertos vezinos la catibaron y la embiaron a esta dicha çibdad de granadada para vender".

43. Citado por García Borx, R., Autos de fe y causas de la Inquisición de Córdoba, 1983, Córdoba, p. 91. 
deçia palabras suçias". El dicho Juan, hablando en primera persona, nos dice: "no quiero ir a confesar que no tengo que dezir mis pecados a un hombre como yo, antes me iría a una encina a confesarme" 44 . Fue procesado "por palabras y cosas diversas".

Podemos concluir que estas fuentes aun estando sesgadas pueden ser reveladoras para el estudio de las personas liberadas en el siglo XVI.

En tercer lugar, nos remitiremos a las fuentes parroquiales, y más concretamente a los expedientes matrimoniales, documentos que aún no han sido analizados por ningún historiador en relación con el estudio de la esclavitud. Desgraciadamente en Granada quedan muy pocos expedientes del siglo XVI, sin embargo conservamos bastantes que corresponden al siglo XVII, los cuales estoy recopilando actualmente. Tomemos por ejemplo, el caso de Ana Ximenez "esclava que fue de Antonio de Salazar veintiquatro desta çibdad" que nos permite oír su propia voz cuando dice "teniendo su amistad del susodicho de más de un año a esta parte y agora queriendo poner en efecto el dicho matrimonio los dichos mis amos porque no obiese efeto ese matrimonio el lunes en la noche que agora paso escondidamente me sacaron de la villa de pliego y me truxeron a esconder a esta çiudad de granada" 45 .

En último lugar volveremos a las fuentes notariales. Entre los documentos que encontramos en los protocolos notariales, podríamos citar las cartas de compra-venta en que libertos y libertas actúan por sí mismos. Por ejemplo, encontramos la carta de compra de una casa en que Pedro Macarruf, tres años después de que testara el dueño ahorrándolo, actúa ahora como liberto. En el documento se aclara "moreno esclabo que fue de Lorenço Macarruf difunto vezino de Granada". El contrato aclara que hace 8 años que se casó "ligitimamente segun orden de la santa madre yglesia con Ynes Dalia" y que con el dinero que Ysabel Macarrafa, viuda de su ex-propietario, le dio y otros ahorros, se ha comprado una casa "en esta dicha çiudad de granada en la colaçion de santa ysabel de los abades de Francisca

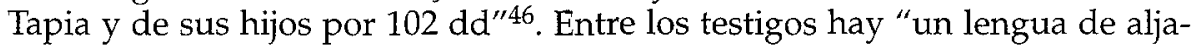
mia Diego Lopez" que hace las veces de intérprete.

También en los protocolos notariales podemos recoger información sobre libertos/as que se ponen voluntariamente a trabajar a través de las cartas de serbiçio. El formulismo común sería el siguiente: "yo Maria de la Cruz de color morena y vezina de granada entro a serviçio con vos Hernando de Paredes relator de esta real audiencia..." ${ }^{47}$, y más adelante se aclara la duración del contrato y el salario estipulado.

44. Ibídem.

45. Archivo de la Curia, Granada, 1957.

46. APG, $\mathrm{n}^{\circ} 150$, fol. $496 \mathrm{v}, 1566$.

47. APG, $\mathrm{n}^{\circ} 200, \mathrm{~s}, \mathrm{f} ., 1575$. 
Por último cabe señalar que entre las facultades que adquieren los libertos y libertas en el momento de su ahorría se encuentra la capacidad de testar. Sin embargo, los testamentos de libertos/as son muy poco frecuentes y desde luego no corresponden al número de cartas de horro, aunque no por ello dejan de ser significativas. ¿Por qué son tan infrecuentes los testamentos de libertas y libertos en los protocolos notariales? En mi opinión, las razones pueden ser varias: a) en primer lugar, la necesidad de un mínimo de dinero para pagar al escribano y las mandas obligatorias del testamento, por otro lado en la mayoría de los casos no hay patrimonio que transmitir; b) otra razón podría ser la falta de conciencia religiosa, es decir el hecho de no entender el testamento como un medio para salvar el alma; c) quizá no saben utilizar los instrumentos legales que le habían sido negados anteriormente y por lo tanto no entra en sus esquemas el testar; d) en último caso, queda la posibilidad de que exista voluntad de afirmarse en su nuevo estatus de libre y aparezcan testando entre los pobres sin hacer referencia a su pasado esclavo a través de las fórmulas que hemos visto anteriormente ("esclavo que fui de...", etc.).

Citaré tres ejemplos de personas liberadas que testan en diferentes condiciones para ilustrar la heterogeneidad de este colectivo. Empezaremos por presentar el testamento de Alonso de Aguilar, un liberto morisco que tenía una panadería con otro morisco llamado Francisco elCambily. Alonso explica que cuando se casó con Beatriz de Aguilar "no reçibi con ella nigun dote porque heramos captivos" ${ }^{\prime 4}$. Tuvo tres hijos con ella, dos varones y una mujer, que fueron libres una vez liberada la madre y que lo acusan de quedarse con los bienes de la misma aunque él lo niega. Más tarde se casó con otra mujer, Isabel de Aguilar, con la que sí tuvo ciertos bienes: una casa en San Idelfonso, una viña en la sierra y 10 ducados. De estos bienes lega la mitad a su esposa, 23.000 maravedises de dote a una hija del primer matrimonio y la viña para Isabel, de su segunda unión. Llama la atención que el apellido de Alonso y el de sus dos mujeres coincide, sin embargo, el hermano de Alonso se llama Diego de Monsalve. En cualquier caso, el testador fue capaz de reunir una cierta cantidad de bienes durante su vida y se casó dos veces.

Otra liberta que testa es Beatriz Hernánde $z^{49}$, que fue esclava del jurado Domingo Pérez. Beatriz no tiene bienes, ni habla de ningún familiar: el albacea es "el cura de la parroquia falleçiere". Tampoco tiene preferencias por una iglesia a la hora de su enterramiento ya que pide que su cuerpo sea sepultado en la "yglesia de la parroquia donde falleçiere"; y sigue las pautas acostumbradas: que le digan "una misa e vigilia e se pague lo que es costumbre", el novenario pagado, las mandas obligatorias ("çinco maravedises") para la redención de los cristianos cautivos en berbería y limosna a la iglesia, en este caso a "San Miguel y la Yglesia Mayor".

48. APG, fol. 945, 1521.

49. $A P G$, fol. $646 \mathrm{v}$. 
Por último, citamos el testamento de Isabel de Carmona ${ }^{50}$, liberta, que se casó siendo esclava y más tarde su marido pagó el rescate. Así nos dice Isabel: "yten digo y declaro que el dicho Juan Lopez mi marido antes que fuesemos casados tuvo mi amistad e conversaçion e despues estando casados pago por mi rescate a alonso de Carmona mi amo nobenta ducados los pago el dicho Juan Lopez mi marido de su trabajo", y sigue más adelante: "yten digo e declaro que antes que yo e el dicho mi marido nos casasemos obimos por nuestros hijos a Juan e a Diego los quales estan en poder del dicho Alonso porque yo no había conseguido libertad e por no ser abidos despues de casados sino antes lo declaro". Además de oír la voz directa de Isabel, volvemos a ver cómo el estatus de los niños depende directamente del de la madre, y no del de "los padres" como dicen numerosos historiadores. Isabel deja a su marido encargado de que libere a los niños y dice: "porque no siendo libres no quiero que hereden". Además deja por albaceas a su marido y a su ex-dueño, quizá para crearles cierta obligación moral a la hora de cumplir su testamento.

Como hemos visto, la realidad de estas tres personas es muy diferente: desde Beatriz que no posee nada ni tiene familia hasta Alonso, casado dos veces y con un cierto patrimonio.

A modo de conclusión, podríamos decir que las fuentes para el estudio de las libertas y libertos moriscos son más abundantes de lo que en un primer momento cabría esperar. Además es muy evidente la variedad de situaciones que se presentan dentro de las relaciones de dependencia y, por tanto, la heterogeneidad entre el propio colectivo de moriscos y moriscas libertos. Heterogeneidad que se basa, como en tantos otros contextos, en razones de índole social, económicas, religiosas y de género. Por ello, creo que es realmente necesario un estudio profundo y amplio que nos desvele la variada realidad existente dentro del colectivo de moriscas y moriscos libertos en la sociedad granadina del siglo XVI.

50. APG, fol. 561r, 1570-1571. 